\title{
THE NEED FOR DIVERSIFICATION OF FORENSIC TACTICAL RULES APPLICABLE TO CRIME SCENE INVESTIGATION
}

\author{
Associated Professor Pavel Palcu, PhD \\ "Vasile Goldiş" Western University, Arad \\ Magistrate Prosecutor at the Prosecutor's Office attached to the Court of Arad
}

\section{(Received April 2017; Accepted June 2017)}

\begin{abstract}
The unprecedented development of cybernetics was concretized by the emergence of computer technology in ways difficult to predict. In this context, the international underworld and organized crime have expanded the area of criminal acts, but equally there were new investigation possibilities for the police and judicial authorities, limiting the role of intuition and flair, of human spontaneity, the center of gravity falling on their ability to use new technology intelligence they have at their disposal.
\end{abstract}

Keywords: crime scene, forensic tactical rule, CFL organization, planning principle, crimes

\section{General considerations}

A true justice in a state of law, requires an optimization of the operation of its components, in compliance with the law and following that eternal and unique goal: finding the truth, and by virtue of this principle, its defense from the harmful effects of any type of crime (Murgu, Stoicu, 2007, 2010).

In this activity, collaboration of responsible factors becomes an implicit condition and requires the use of those means and methods to ensure the objectivity of the investigation close to that of the researcher found in a scientific laboratory.

To put into logical relations the terms of the investigation equation, it is clear that operating through the human psyche, investigations and criminal investigations will not lead to the kind of truths that exact sciences operate with in a laboratory. Or, precisely if elements of these sciences are involved in the activity of the judicial authorities, relativity is limited and probation will have a quality neighbor with certainty (Larie, 2010).

This need led, more than a hundred years ago, to the emergence of a science, forensics, through which, adapted to the specific context of judicial investigation, the specific methods of other sciences are used to assess all evidence, the status quo belief formation and the establishment of relevant and conclusive evidence in court.

At the end of the second millennium, contemporary human society pays an unimaginable tribute from over half a century ago of unprecedented growth of crime and its new forms of expression, more and more sophisticated and aggressive forms of organized crime. 
Equally, forensics evaluation and its contribution to the judicial process must take into account several key elements of the status quo and evolution of contemporary society.

The first aspect is the globalization of all socio-economic phenomena, including the crime internationalization plan, and, correspondingly the fighting back of judicial bodies.

Consequently, this triggers measures that led to consolidation of the cooperation between national police in complex type like Interpol, Europol, etc.

A second issue, related to the first, is the unprecedented development of cybernetics, by the emergence of computer technology in ways difficult to predict. In this context, the international underworld and organized crime have expanded their area of criminal acts, but equally there were new possibilities for the police and judicial investigation, limiting the role of intuition and flair, of human spontaneity, the center of gravity falling on their ability to use the intelligence of the new technology at their disposal (Duta, 2001).

Man, however, cannot be replaced by computer, be it even for the fact that primary data they operate with are given by his own work in identifying and collecting evidence at the scene and ultimately the one who decides the solution all by himself. The computer, due to the program inoculated by man provides much faster and more reliable analysis possibilities and contributes decisively to achieving success (Lechat, 2000).

Regarding the term "forensic tactical rules", specifications should be made regarding the content, the meaning of the term "rule" and the etymology and meaning of the adjective "tactical".

In the dictionary, "rule" means "to put in order, to arrange, to arrange, to organize" and as specialty, the term refers to an activity of "putting in place a mechanism to make it work regularly" (Coteanu, 1984).

The etymology of the adjective "tactical" comes from the French word "tactique" and refers to "the study, organization, training (...), to meet the goals set with maximum efficiency." In other words, generally speaking, "tactics" includes all the means used to succeed in an action.

Forensics tactics, an integrative part of forensic science is constituted by a system of procedures and specific rules based on the provisions of the criminal procedure law and the general experience of judicial authorities, developing methods regarding prosecution work, the opportunity and performance of prosecution activities, for example, crime scene investigation, search, reconstitution, others (Mircea, 2001).

Forensic tactical rules of crime scene investigation could present the following key elements:

- they are part of the overall forensic tactics; 
- they represent a specific procedures system based on strict adherence to the provisions of the criminal procedure law and generalized experience of judicial bodies;

- they require a certain conduct in order and a concrete way of making criminal procedure acts in crime scene investigations;

- they seek and facilitate the aims of this work; direct knowledge of the crime scene; discovery, establishment and lifting of traces.

So, trying to define forensic tactical rules applicable in crime scene, we can say that they represent a system of specific procedures based on the provisions of the criminal procedure law and general experience in forensic research practice, through which a certain conduct regarding opportunity and sequence, is imposed as well as how exactly to perform specific acts of investigation in order to achieve the research purpose at the crime scene.

Tactical rules of forensic research, as it is natural, do not have an express provision in the regulations, they are the result of judicial practice and experience gained over time, which in solving some cases strategy was adopted the appropriate strategy for the given state of facts.

Failure of one or more tactical rules, unlike failure to comply with procedural rules, does not entail the nullity of made paperwork with this omission, the only sanction that can occur being the delay and difficulty in resolving the case, or failure to identify offenders (Mircea, 2001).

\section{Classification of rules tactical forensic crime scene investigation}

Without claiming limiting criteria, but illustrative, tactical forensic rules classification applicable by measures taken when conducting crime scene investigation may be achieved as follows:

a) After their application field, forensic tactical rules divide into two categories:

- general forensic tactical rules;

- specific forensic tactical rules, in turn, are of two kinds:

- prior to conducting the crime scene investigation;

- applicable during the actual crime scene investigation.

b) After the phase in which crime scene investigation takes place, tactical rules can be divided into two categories:

- forensic tactical rules applicable thorough measures in static phase;

- forensic tactical rules applicable through measures in dynamic phase.

c) After the place where the judicial body is when applying these tactical rules, they divide into two categories:

- rules applicable to criminal tactical measures at the headquarters of the judicial body;

- forensic tactical rules applicable by measures taken at the crime scene. 
d) Considering the organism that applies forensic tactical rules, they fall into two categories:

- forensic tactical rules applied through eliminary measures by the authorities first arrived at the crime scene;

- forensic tactical rules provided and applied by the judicial body.

\section{Conclusions}

Crime scene investigation is an initial and immediate activity, namely the primary investigation activity related to crime comitting. It is situated in a time when judicial bodies do not know anything, or is in possession of reduced, unverified information on how to commit the crime (Stancu, 2012).

Immediately after arriving at the scene and conducting preparatory measures, the investigation team searches the crime scene. Crime scene investigation requires along with careful and conscientious preparation, compliance with tactical general rules applicable throughout the investigation in order to achieve the intended purpose (Mircea, 2001).

General tactical rules of crime scene investigation are essentially the following: urgency, the objective comprehensive and detailed feature of the investigation, revealing and full fastening all aspects and material evidence which may serve to clarify the case and planning the activity of the investigation team, compliance with moral codes and observing the behavior of the offender present at the crime scene when necessary.

The actual investigation of crime scene will be made in strict compliance with the general tactical rules mentioned above. These rules shall be followed, regardless of the offense investigated, even if at the crime scene others previously entered. Application of tactical rules is made also depending on the specific of the invetigated area (open or closed places) (Mircea, 2001).

\section{Bibliographic references:}

1. I. Coteanu, collectively, The Explanatory Dictionary of the Romanian Language, Ed Socialist Republic of Romania Publishing, Bucharest, 1984

2. T. Duță, Murder investigation in sec. XXI, Ed "Little Star" Publishing, Impex SRL, Bucharest, 2001

1. M. Larie, Realities and perspectives in forensic work of prosecutors, "Little Star" Publishing, Impex SRL, Bucharest, 2001

3. R. Lechat, "Enque criminel (Criminal inquiry)" Ed Modulo, Mont-Royal (Quebec), Canada, 2000, p.68 et seq., above cited,

4. I. Mircea, works cited, p 216, Forensics, Lumina Lex Publishing, Bucharest, 2001

5. S. Murgu, N. M. Stoicu, Constitutional law and political institutions, Cordial Lex Publishing, Cluj-Napoca, 2007, p.184 and seq.; 
Palcu P. (2017)

The need for diversification of forensic tactical rules applicable to crime scene investigation

6. S. Murgu, N.M. Stoicu, State of law and justice in the acceptation of the Council of Europe, in the volume "Dimensions of culture and legal practice", Dacia Publishing, ClujNapoca, 2010, p. 182-190

7. P. Palcu, Tactical considerations on preparation, stages and technical means of fixing crime scene investigation, Arad Universtity Press Publishing, 2004

8. E. Stancu, works cited, p 213, Bucharest scientific investigation of crime, forensics course, Typography of the university Bucharest 2012 